\title{
Implementation of CRM systems in Portuguese Municipalities
}

\author{
JORGE DUQUE*, JOÃO VARAJÃO****, FILIPE VITOR***** \& \\ CAROLINE DOMINGUEZ* \\ *University of Trás-os-Montes e Alto Douro, Vila Real, Portugal, **Centro ALGORITMI, \\ Portugal, ***INESC-TC/UTAD, Portugal
}

\begin{abstract}
Customer relationship management is a business strategy which dynamically integrates a set of services with the purpose of creating value for the organisation and for their customers. In Portugal, the 2009/2010 edition of 'Simplex for Municipalities', the action plan carried by the Portuguese government through the Secretary's Office of State for Administrative Modernisation, makes a commitment to promote a set of initiatives in order to help citizens using the public services. This process intends to reduce costs of context which burden the economic activities, making way for the modernisation of administration. Customer relationship management assumes a central role in this context. This paper presents the main results of a survey that was carried out with Portuguese municipalities, aiming a general characterisation of the adoption of customer relationship management systems, covering several aspects, from the motivations for CRM adoption to the obtained results. The improvement of the relationship with citizens and a higher information quality are some of the most important results obtained by municipalities.
\end{abstract}

KEY WORDS: CRM, CzRM, municipalities, survey, citizens

\section{Introduction}

Managing the relationship with customers has become a priority for many organisations. Taking in account highly competitive markets, companies invest substantially in customer relationship management (CRM) systems. In other words, they invest in the management of the relationships with their clients (Bohling et al. 2006).

Several studies validate the belief that CRM is nowadays a critical success factor for business performance (Sin et al. 2005, Shi 2006, Saini et al. 2009). From a company point of view, the existence of a culture oriented towards clients is vital in order to increase the quality of information, and to create, promote and disseminate knowledge about the costumer. The existence of a clear strategy of relationships is also essential (Tzokas and Saren 2004).

Correspondence Address: Professor João Varajão, UTAD, Engenharias, Vila Real, Portugal. E-mail: joao@varajao.com

(C) 2013 Taylor \& Francis 
Having an efficient relationship management system frequently implies that companies change their own behaviour radically and define a consistent CRM strategy (Chalmeta 2006).

As it happens with companies in general, public organisations should also benefit from CRM features. These organisations do not pursue commercial objectives, but their main concerns are cooperation, availability, loyalty and interaction with citizens.

In this context, CRM (or more precisely in the case of public institutions: CzRM - citizen relationship management) allows organisations to have a deep knowledge about the citizens they interact with. Thus, it implements a public service of excellence, improving the quality and productivity (MC 2007).

Structured in a prompt, consistent and agile basis, the CzRM provides access to information and services, regardless of the channel used by the citizen to communicate with the organisation. It allows the strengthening of ties and cooperation between public organisations and their citizens through a greater operational efficiency, supported by an environment which encourages innovation within the organisation. That is why CzRM strategies must be multi-channelled, developed from an overall citizen comprehension, and oriented to citizen's needs, rather than the needs of the organisation (Xavier 2002).

The implementation of CzRM requires a deep change of the public organisations' inner culture and a reorientation of the vision by their state bodies. The attitude and mentality of civil servants must change, allowing a citizen-directed service, eliminating bureaucratic procedures and focusing more on the actual needs of the citizens. The CzRM permits putting the citizens in the centre of the activity of public organisations (Milakovich and Gordon 2004).

The priority of municipalities should consist in improving the quality of the life and well-being of society, in their own affirmation through innovation and in their capacity to attract active, participative citizens, as well as dynamic and supportive economic agents. To do so, public organisations need transparent and agile management models based on the optimisation of processes and on the reorientation of the activities towards citizens and companies, eliminating procedures which do not add value (GSEMA 2009).

The implementation of the CRM concept in a public organisation, and more specifically in Portuguese municipalities, requires the review of its interaction processes so that the citizen becomes the central element. Information should be organised by citizen and not by transaction, so that any citizen can get the same information regardless the means by which he communicates with the municipality. In each interaction with a citizen it should be possible for the municipality to learn more about that citizen, enlarging the information on his habits and enabling strategic decision-making.

Establishing a relationship with citizens through the internet is also an interesting challenge that some municipalities have already adopted and 
implemented. A good public service provides citizens with what they need and when they need it in order to best satisfy them. The emergence of egovernment has increased the choice of means to interact with local public services (one stop shops, call centres, websites, e-mail, kiosks, digital television, mobile, SMS, etc.), allowing citizens to contact municipal services, regardless of location and time, so that they may have access to the desired information (Lent and Arend 2004).

Aiming at a better understanding on the adoption of CRM systems by Portuguese municipalities a survey was carried out. The main motivations that led to the implementation of CRM systems in municipalities were identified, as well as the main criteria used to select the CRM solutions, the results achieved with the CRM implementation, the main faced difficulties, success factors in CRM implementation, among other aspects. The obtained results, presented and discussed in this article, are not only important to have an insight of the current state-of-the-art, but also enable municipalities to better plan future actions of CRM adoption.

In section 2, several key concepts are presented about CRM systems. In section 3 and section 4, the research method is detailed and the results regarding the adoption and implementation of CRM systems in Portuguese municipalities are discussed. Finally, in section 5, some final remarks are elaborated.

\section{CRM - customer relationship management}

Over the last 15 years CRM has developed into an area of major relevance (Frow and Payne 2009). Essentially, CRM enables an organisation to find clients, to know them better, to provide them with better services and to anticipate their demands (Goodhue et al. 2002). However, CRM has different meanings according to different authors (Winer 2001) and organisations address CRM issues also in different ways. For example, for some CRM is considered as a software, while for others it is an essential part of the business. Therefore, there is a need of a holistic approach from organisations to integrate the information technology (IT) with their business processes in the delivery of services to their clients.

Some authors show concern about the different concepts used to define CRM. This is due to the fact that the objectives of companies in relation to CRM are intimately related to their understanding of the concept. It is thus important to refer that CRM was largely disseminated by systems consulting firms and software manufacturers, which created essentially a technological perspective (Payne and Frow 2005, Ngai 2005). For other authors, the CRM concept is not consensual, underlying that companies address CRM strategy in different ways: some companies see CRM as a technological tool, whereas others understand it as a business strategy (Teo et al. 2006).

The main feature of CRM lies on increasing the opportunity to use customers' data (in order to understand them better) and thus be able to 
implement more effective business strategies. The IT in this case is seen as resources that allow the integration between people, operations, processes and marketing competencies, spread in the different functions/departments of the organisation (Payne 2006, p. 438).

The concept of CRM has evolved in such a way that it should be seen as a strategy to maintain a long-term relationship with the customers. Broadly, CRM can be seen as a combination of a business and marketing strategy that integrates people, process, technology and all business activities, with the purpose of attracting and retaining customers, providing analytical capabilities, reducing costs and increasing profitability, by the consolidation of the principles of customer loyalty (Wahab et al. 2010).

One of the main problems though is that there is not a typical model which can orient companies in CRM implementation. Companies are different from one another, having their own culture and business processes. Therefore it is important that CRM is not considered as a magic solution which will solve all the company's problems. Instead, it should be studied and analysed from a perspective of its benefits and impacts on the company. The implementation of a CRM strategy requires a lot of work to be successful. Once a company has decided to adopt a CRM strategy model, it must give priority to the training and hiring of competent human resources, with the adequate knowledge and abilities to satisfy costumers' needs through appropriate products and services (Mendoza et al. 2007).

CRM is used to collect and analyse data, creating a greater interaction with the client (King 2006). As it happens with private companies, CRM is fundamental for municipalities: the purpose of which is to ensure and optimise the relationships with their citizens and to promote citizenship (Schellong 2005).

For Xavier, Gouveia and Gouveia (Xavier et al. 2004), the municipalities which do not have the ability to generate interactions with their citizens in order to manage and process information will hardly establish effective relationships with them. It is useless to provide websites or contact centres for citizens if they do not provide systems capable of collecting, processing, managing and delivering the information. The same authors also refer that there is no point in not seeking to achieve, as to what the relationships with the citizens is concerned, the benefits that CRM already demonstrated in the relationships between companies and their customers. That is to say that the municipalities with CRM are endowed with more knowledge and capacity to meet the citizens' needs. Moreover, residents benefit from new offers and improved levels of services. That is why it is important that municipalities consider the implementation of customer relationship management systems adapted to citizens.

Citizen relationship management comes from the CRM concept of the private sector applied to the public sector (Schellong and Langenberg 2007 , Silva and Batista 2007). CzRM has been defined as an IT strategy that focuses the citizen in general. Its purpose is to maintain and to optimise the 
relationship with households and to encourage citizenship (Schellong 2005). The objectives of CzRM are, among others, to improve citizens counselling, to reinforce the sense of responsibility and change in the relationship municipality-citizen (Schellong and Langenberg 2007). It allows to understand the concerns of citizens, to improve the performance of the services, to encourage a greater participation of the public, to ameliorate and control the internal management of organisations (Young et al. 2007, Chu et al. 2008, Foss et al. 2008, Richter and Cornford 2008).

The adoption of CRM has not been as widespread in the public sector as in the private one. The absence of market incentives, the need of higher levels of responsibility and the existence of multiple and conflicting objectives have set back the adoption of these information systems (Pan et al. 2006). However, the orientation of private companies towards client service influences the expectations of citizens regarding public sectors which use CzRM (Schellong 2005).

\section{Adoption of CRM systems in the Portuguese municipalities}

To characterise the adoption of CRM systems by Portuguese municipalities, a questionnaire was elaborated and sent to all municipalities of continental Portugal, Azores and Madeira islands. This questionnaire studied and analysed the reality of the implementation of CRM systems in Portuguese municipalities.

Out of the 308 municipalities which were contacted between 21 March 2009 and 30 April 2009, 64 valid responses were received which is equivalent to an approximate $21 \%$ rate of response. Among these 64 municipalities, only nine reported using CRM systems, which is equivalent to $14 \%$ rate.

It was noted that Portuguese municipalities use mainly CRM systems from large vendors (e.g. Microsoft, Oracle). It is interesting to notice that the use of open source systems was not found, which can be explained by the fact that Portuguese municipalities do not usually use this kind of software.

The main results obtained in the study carried out are presented in the next sections.

\subsection{Satisfaction from the adoption of CRM systems}

Regarding the level of satisfaction in the adoption of the CRM system, municipalities were asked to classify a range of aspects on a Likert scale of 0 to 5 , with 5 indicating the highest degree of satisfaction and 0 the lowest. Results are presented in Figure 1.

Seven of the nine municipalities with CRM considered their level of satisfaction as 4 . This indicates that these municipalities are getting good results from their CRM. No answers were obtained below level 3, which suggests that the global expectations with the CRM are being satisfied. 


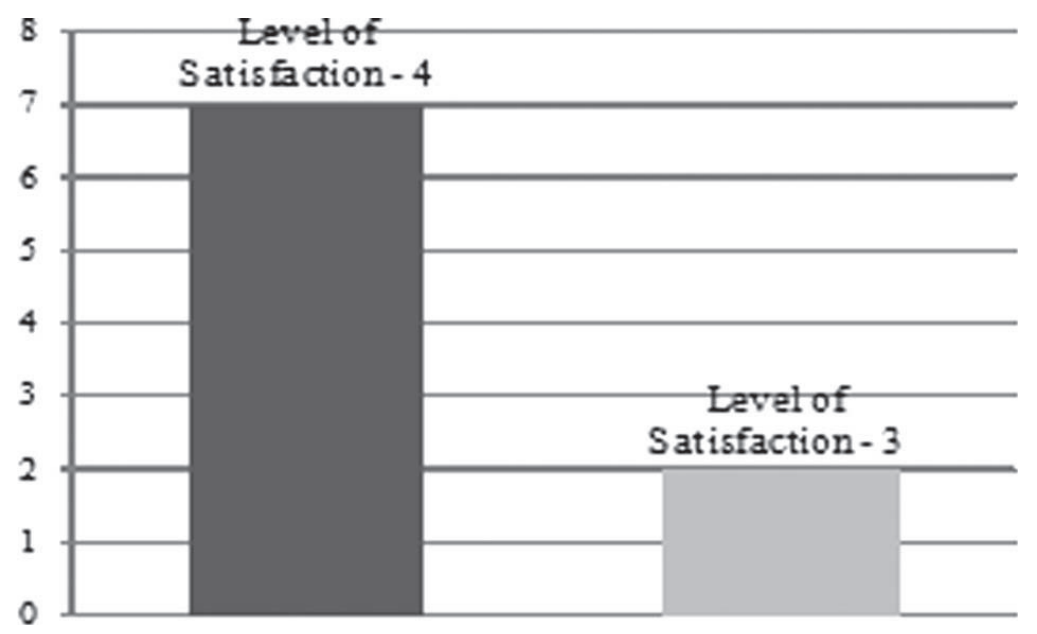

Figure 1. Satisfaction from the adoption of CRM systems.

However, the fifth level of satisfaction was not reached, which means that there is still room to improve.

\subsection{Motivations which led to the implementation of CRM}

To identify the main motivations which led to the implementation of CRM in municipalities, it was asked to indicate, among the aspects listed below, the level of motivation, using a Likert scale from 0 to 5 , where 5 indicated a strong motivation and 0 indicated the absence of motivation. The motivations presented to participants were:

- increase the confidence of citizens on services;

- improve the global satisfaction of citizens;

- enable greater interoperability between the existing systems in the municipality;

- send individual marketing messages;

- improve the services provided to the citizens;

- enable personalised services;

- improve internal processes;

- increase the quality of information;

- reduce costs in providing services;

- not be outdone by other municipalities.

In average, the criteria 'increase the quality of information', 'improve the services provided to citizens', 'improve internal processes' and 'enable greater interoperability between the existing systems in the municipality', were considered the most relevant ones for motivation of the implementation of the CRM system, as it is possible to observe on the chart summary of Figure 2.

The criteria with the four higher average values (between 4.44 and 4.56) are key aspects to any organisation and all municipalities assigned them a 


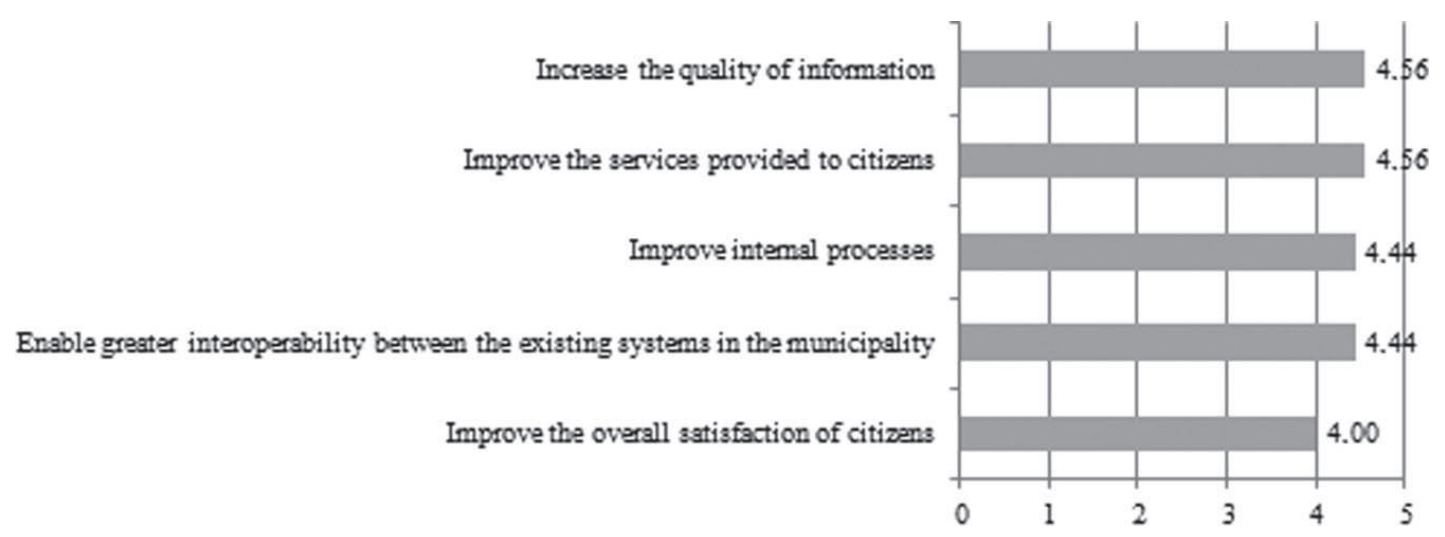

Figure 2. Main motivations which led to the implementation of CRM.

grade 4 or 5. Municipalities feel the need to concentrate the information of citizens, which is many times scattered through several departments and geographically distant, creating a more uniform way to access to the information - either from the employees of the municipality, either from who seeks its services.

Improving the service provided to citizens is a priority. By implementing a CRM system, it enables municipalities, among others aspects, to have a two-way functionality, allowing them to have an immediate feedback from the citizens, thus facilitating the management of priorities. It also enables a bigger and better management of data, a global and integrated vision of the organisation and the knowledge of some critical points in the municipality. Those are strong motivations for the implementation of CRM systems.

In terms of internal operation, a CRM project helps the municipality to revise processes and improves resources management. It also forces the municipality to increase its capacity of response, in particular the way orders made by citizens are treated and accompanied. For what is possible to see, there is a clear concern at the internal level, to treat the information through the CRM system, taking in account other already existing systems.

The criteria 'not be outdone by other municipalities' and 'send individualised marketing messages' do not constitute fundamental reasons for adopting CRM, since all municipalities assign them lower levels of classification. Nevertheless, it is interesting to note that, regarding 'not to be outdone by other municipalities', some municipalities consider important the creation of a different image on how they deal with their citizens as a positive mark. As to the item 'sending individualised marketing messages' is concerned, it depends on the region where the municipality is located and the target public. However, some municipalities consider operational marketing one of the main functions of CRM systems. Getting closer to citizens through customised messages and receiving in return as much information as possible, are certainly objectives of these municipalities through their CRM systems. 


\subsection{Criteria used in the selection of CRM systems}

So as to identify the main criteria used by municipalities to choose CRM systems, participants were asked to indicate the most relevant ones they considered when deciding for the adoption of a system in their organisation:

- cost of software/hardware/services;

- easiness of implementation;

- easiness of utilisation;

- set of available features;

- compatibility with existent hardware;

- compatibility with existing software;

- flexibility and possibility of future upgrading;

- supplier's characteristics;

- quality of the support offered;

- quality of documentation;

- maintenance and support costs;

- used technology (e.g. internet);

- recommended by a superior entity.

'Easiness of utilisation', 'cost of software/hardware/services', 'quality of the support offered', 'flexibility and possibility of future upgrading' and 'set of available features' were the most cited criteria according to the summary chart of Figure 3.

All the other criteria were not considered as important, as they are cited by less than one-third of the municipalities.

\subsection{Results of the implementation of CRM}

The results that municipalities obtained through the implementation of the CRM is very important since it highlights in which areas municipalities were able to improve: standardisation of processes, quality, productivity, availability, decision-making, architecture of information systems, removal

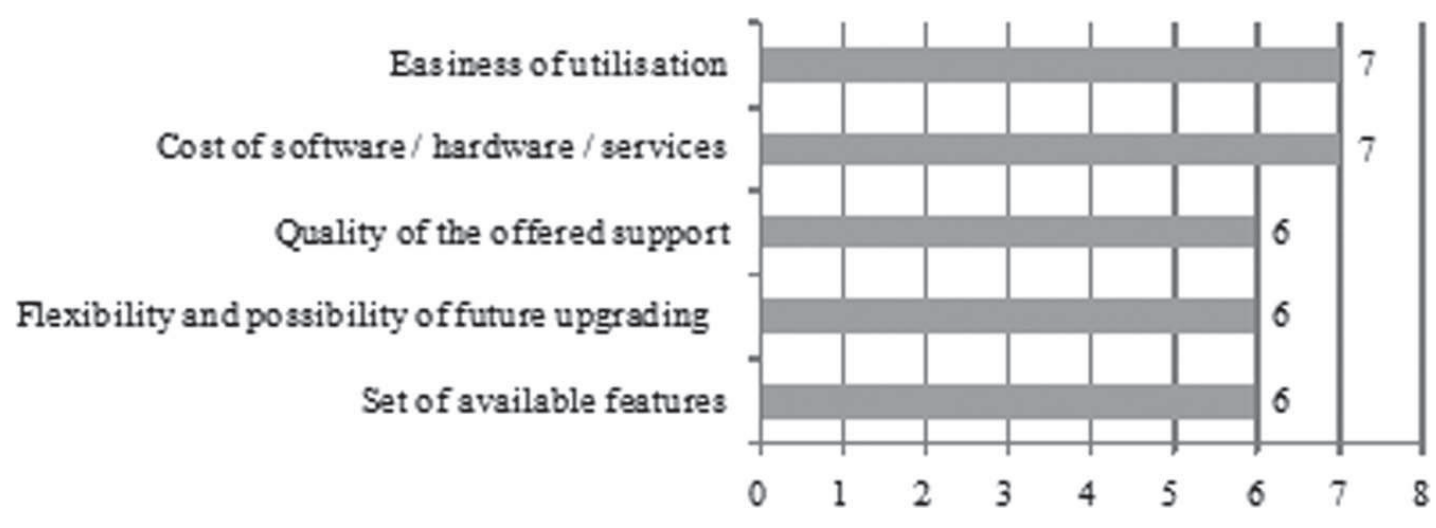

Figure 3. Main criteria used in the selection of CRM systems. 
of redundant activities, interoperability, costs reduction, citizen's satisfaction, etc.

Every participant was asked to select the most relevant criteria among the following ones:

- standardisation of processes in the municipality;

- improvement of the global level of citizens' satisfaction;

- definition of customised marketing messages;

- improvement of the service provided to citizens;

- creation of customised services;

- improvement of internal processes;

- improvement of quality of information;

- increased productivity;

- improvement of decision-making processes;

- removal of redundant activities;

- reduction of time response to requests;

- reduction of costs;

- improvement of the architecture of the information system.

Each of the nine municipalities ranked these criteria from 0 to 5 , with 5 indicating a significant result, and 0 indicating no result. In average, the results of CRM implementation are significant.

As it is possible to observe in Figure 4, out of the 13 assessed criteria, nine achieved an average relevance equal or greater than 4 . It is possible to conclude that the results met the expectations of the municipalities with the CRM implementation, achieving the previously set goals. Regarding the criteria 'improvement of the architecture of the information system', 'reduction of costs', 'creation of customised services', and 'definition of customised marketing messages', these were in average the less important results.

\subsection{Difficulties in the implementation of the CRM}

This section analyses the difficulties faced by municipalities in implementing the CRM. The participants had to rank the difficulties they felt among the following ones ( 5 indicated a relevant difficulty, 0 indicated no difficulty):

- poor service delivered by the supplier (e.g. lack of response);

- a problematic data migration;

- complexity of the integration with other systems;

- slower process than expected;

- necessity of forcing organisational change;

- slow learning of system use;

- resistance to changes by users;

- security and confidentiality of information endangered; 


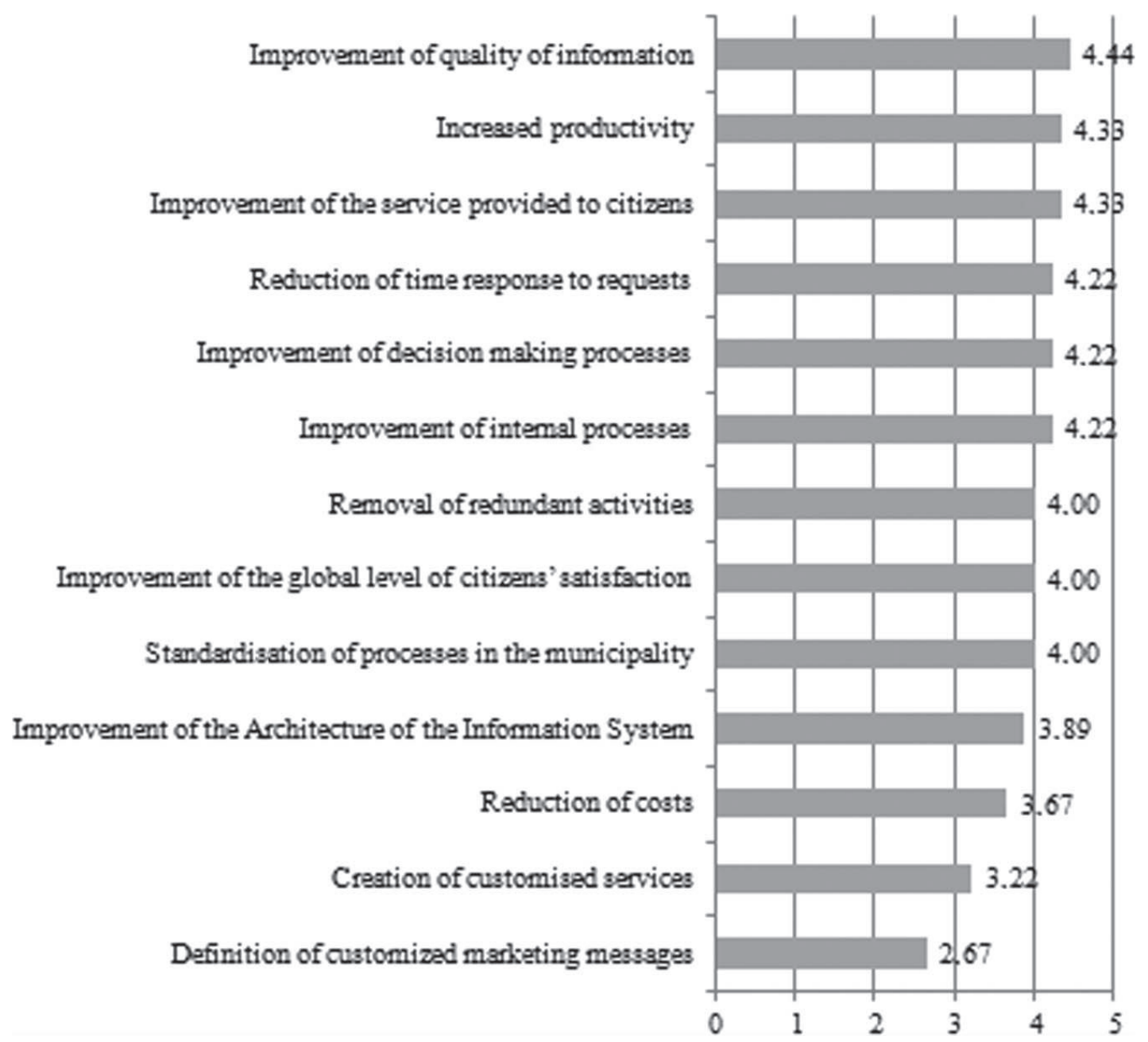

Figure 4. Results of the implementation of CRM.

- inadequate identification of requirements;

- lack of detailed information on the system (e.g. user's manuals);

- failure to meet user's expectations (e.g. in the requirements);

- dependence of the municipality on the software;

- problems with the project team (e.g. high turnover, lack of experience, etc.);

- occurrence of unanticipated costs;

- departments see their overall performance decrease;

- inappropriate existing technological infrastructure in the municipality.

As it is possible to see in Figure 5 through the global average of the criteria, the difficulties with the implementation of the CRM system were not very significant.

'Slower process than expected', 'resistance to changes by users', 'complexity of the integration with other systems' and 'necessity of forcing organisational change' were the more relevant difficulties. This is understandable since the municipalities' processes and systems are complex and they hinder interoperability with CRM. 


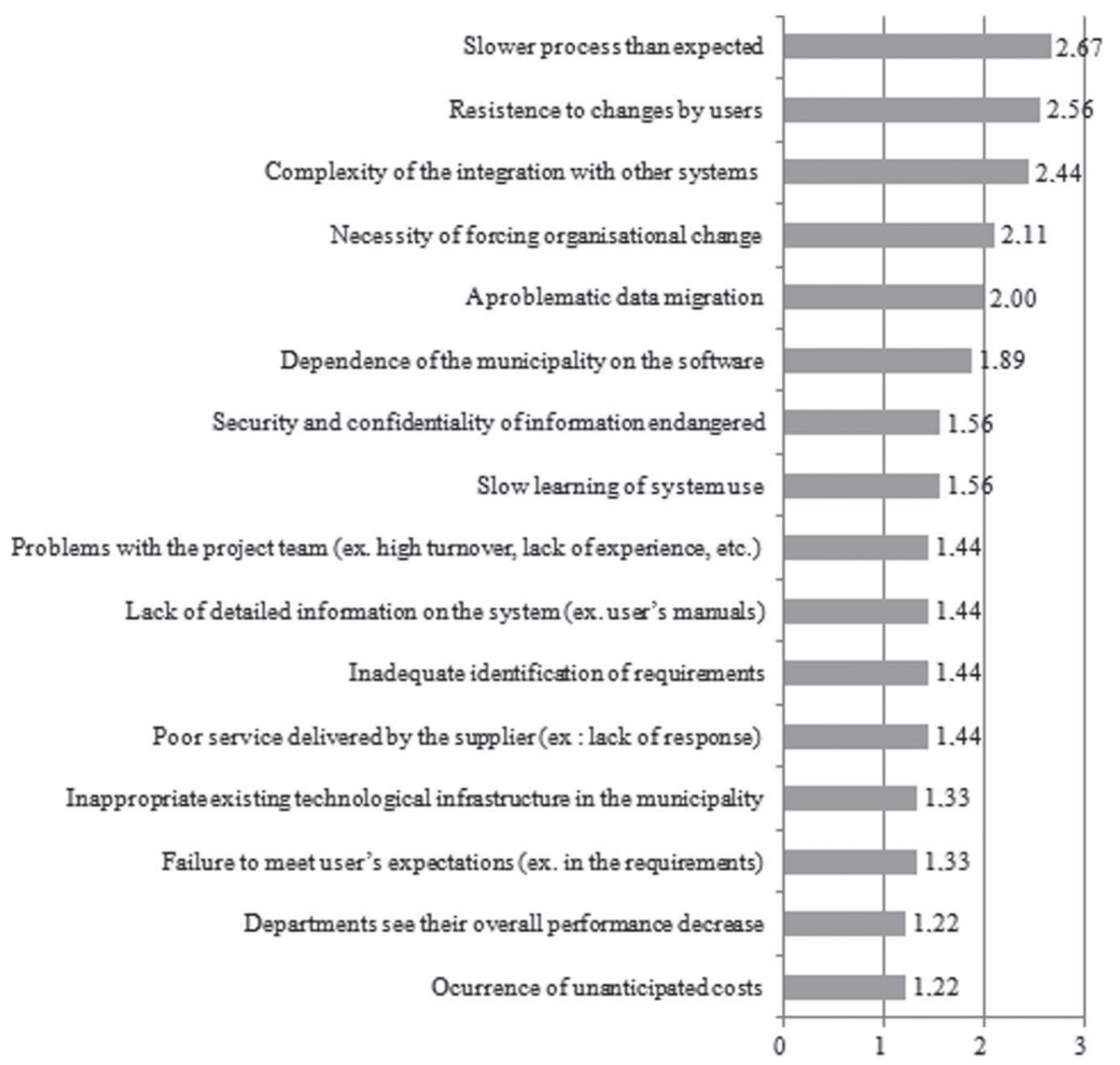

Figure 5. Difficulties in the implementation of the CRM.

The criteria 'departments see their overall performance decrease' and 'occurrence of unexpected costs' were graded as non-relevant.

\subsection{Success factors in CRM implementation}

To identify the success factors in CRM implementation, each participant was asked to rank the following ones from 5 to 0 , where 5 indicates a great importance and 0 none:

- adequate selection of suppliers for the implementation;

- reconsider the processes of the municipality;

- strong internal project team;

- accurate process of solution's selection;

- support of the municipality's board;

- realistic budgets and timetables;

- adequate user's training;

- use of good principles of project management; 
- comprehensive knowledge of the reality of the municipality;

- effective communication with users;

- rigorous contracting process;

- comprehensive knowledge of the current information system;

- alignment of IT with the overall strategy;

- rigorous contract management.

In Figure 6, the average values of the different factors stand all around level 4 , that is to say that the variance is low.

'Effective communication with users' is a very important factor in any project to be developed. Users should be involved in the work to be implemented since they are the ones who will use the system. That way, a full array of problems may be anticipated or even avoided. Tests should also be performed with the participation of final users. It is important to accept criticism and suggestions from users in order to improve the system's design.

'Support of the municipality's board' (or the top management) should be always present in preparing a project. Their lack of involvement could be the

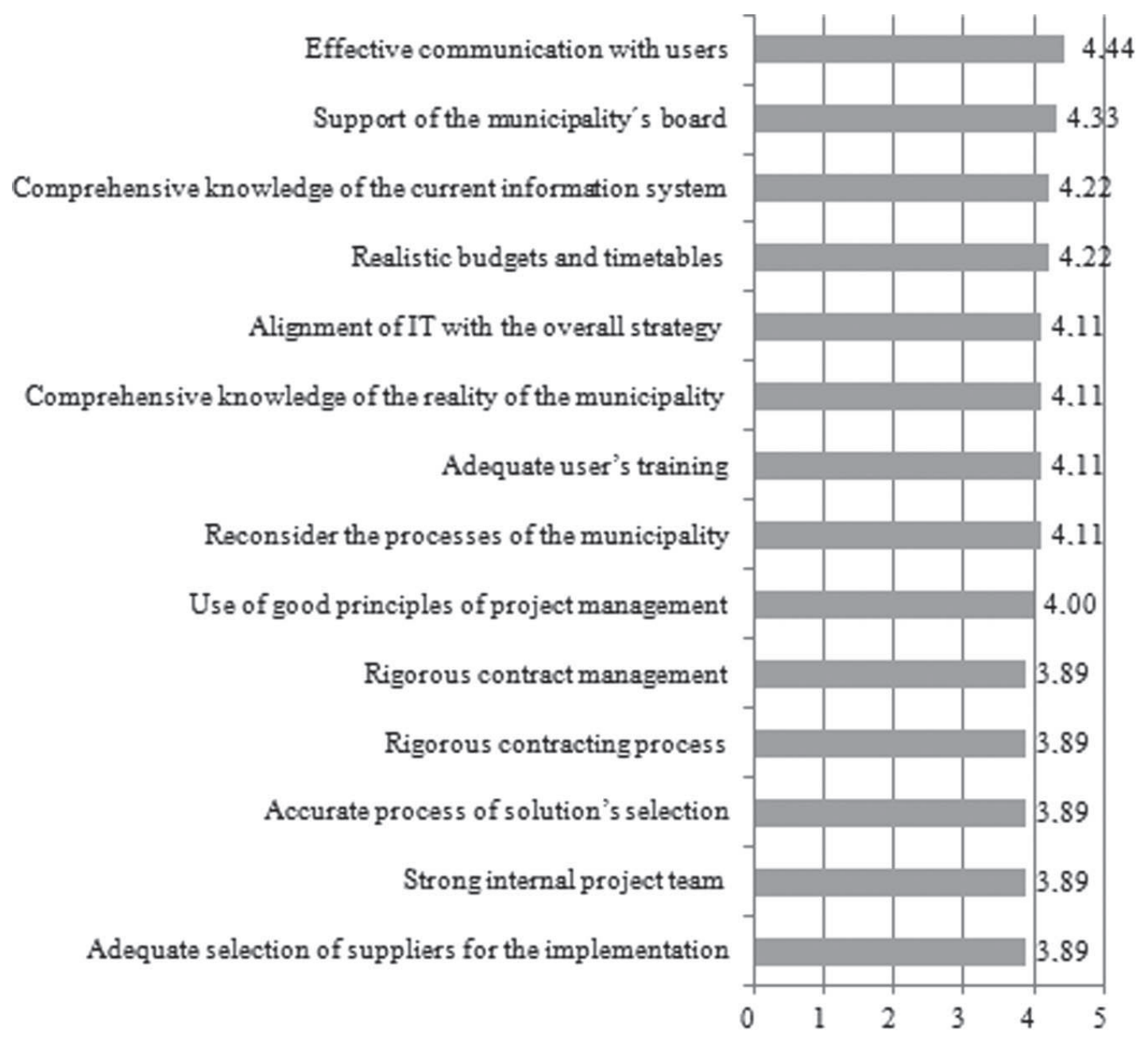

Figure 6. Success factors in CRM implementation. 
first step to failure. It is essential to keep top management informed about all the procedures, starting in the early stage of the project going through the development and implementation ones, in order to get feedback of what is being done.

'Comprehensive knowledge of the current information system' and 'realistic budgets and timetables' are also critical for the success of any project. Not meeting these points brings problems both to the project and to the organisation. When trying to implement a new solution which will enable to increase the quality of internal and provided services and to turn those same services more accessible to citizens, processes should not be delayed otherwise people and the organisation can be at stake.

\subsection{Criteria used in the selection of CRM systems suppliers}

This study also sought to identify the main criteria used in the selection of CRM systems suppliers. Each participant chose a set of relevant criteria (up to 5).

For the municipalities the most relevant criteria used in the selection of the CRM supplier are: supplier's ability to ensure the necessary services, supplier's experience in the activity area of the municipality, supplier's ability in providing support and after sales services and supplier's experience regarding the organisation's current technological environment.

Figure 7 presents the ranking of the most relevant ones, being possible to see that 'supplier's ability to ensure the necessary services' is the most highlighted one. Municipalities seek suppliers with some experience in the field and which are already established partners.

\section{Discussion}

This study showed that only a few Portuguese municipalities had a CRM system implemented. Therefore it was sought to understand the experience of those that had a CRM system implemented. A set of questions were formulated: what type of CRM was implemented, approximate number of users, level of satisfaction, main motivations for the adoption of a CRM

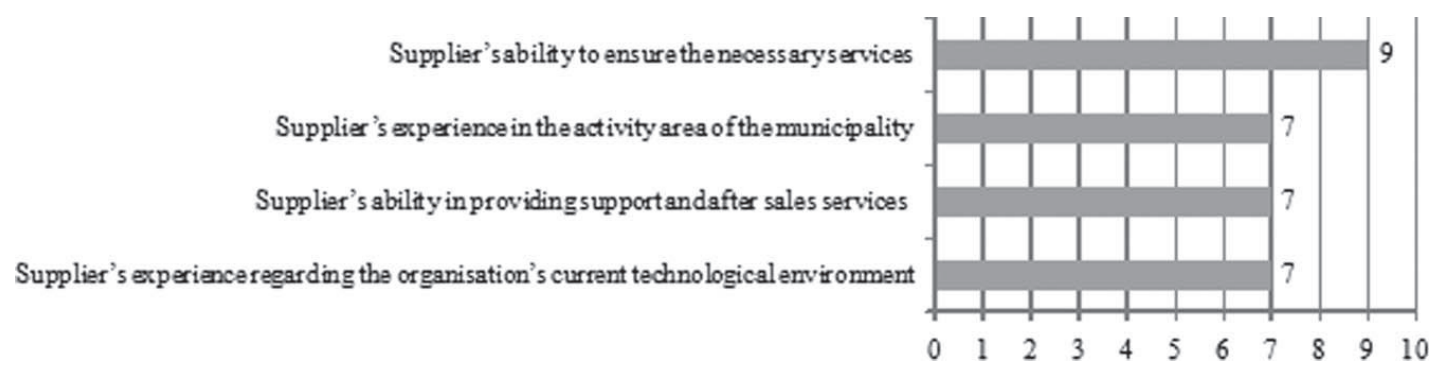

Figure 7. Main criteria used in the selection of CRM systems suppliers. 
system, criteria of selection of the CRM system, results, success factors, criteria of suppliers' selection.

Through the analysis of the answers to the applied questionnaire it was possible to obtain the following results. The municipalities that implemented CRM systems showed high levels of satisfaction regarding to their performance. The main motivations for implementing a CRM system were the following: increase of the information quality, improvement of services delivered to citizens, improvement of internal processes, and the possibility to a greater interoperability between the implemented systems in the municipality. As to the criteria used to select the CRM system, the following ones were pointed out as most important: ease of use, software/hardware/services costs, quality of the support, scalability, flexibility for future changes and set of available features.

As to the results attained through the CRM system, the main ones were pointed out as being the improvement of the information quality, increase of productivity, improvement of services delivered to the citizens, although other ones were also mentioned. Regarding the difficulties experienced in the implementation of the CRM system, municipalities did not highlight one in particular, showing that they are, in general, of little importance. Regarding the success factors for the implementation of a CRM system, which have to do with all the procedures that must be taken in account from the beginning until the closing of a project, the following items were mentioned as most relevant: efficient communication with users, presence of senior management support, knowledge of the existing information system, among others. In the selection of the supplier for the CRM system, its capacity of ensuring the necessary services and of providing good support and after-sale service, its experience in the activity area of the municipality and in responding to technological changes in the municipalities, are the principal criteria which were pointed out by the participants.

CRM systems still do not have a strong presence in the Portuguese municipalities. This study sought also to find out the reasons for such a situation. The principal motives presented by the municipalities which did not have a CRM system implemented were the following ones: considerable amount of investment needed; implementation of a CRM system is being planned; the municipality services are being restructured. Although some municipalities use traditional techniques to deal with the information and to interact with their citizens, they are not as powerful and efficient as the CRM system. Most municipalities without CRM systems have the intention, in a short future, to implement one, demonstrating their interest in improving the relationships with their citizens.

\section{Conclusion}

The services-oriented evolution of the private sector has influenced the expectations of 'customers' in relation to the public sector (Schellong 2005), 
making CRM nowadays an important tool for municipalities to meet and anticipate citizens' needs.

For a better understanding of the adoption process regarding CRM systems, a questionnaire was developed and sent to Portuguese municipalities, serving as the basis of this study. The main objective was to assess several aspects of the CRM adoption in theses public organisations.

Through the obtained answers and some additional evidence, it was clear that the implementation of CRM systems enable to upgrade and optimise municipal service operations, to improve their services to citizens, to promote the interaction between different public administrations and to enhance the quality of citizenship.

The municipalities which adopted CRM systems showed, after their implementation, the development of closer ties with their citizens and a higher quality of information. Greater interactions between citizens and the organisation, as well as greater interoperability between existing systems, were also experienced. Municipal internal processes and productivity have also improved. However, the study identified a very low percentage of adoption of CRM systems by municipalities, showing that there is still a lot to be done in this field.

As a future work proposal, it should be important to continue to follow the evolution of the CRM adoption in municipalities, repeating the survey in Portugal and in other countries, since it will enable to compare different realities and to find best practices. It would be also interesting to explore if there is a correlation between some of the variables studied (for instance, between the motivations of CRM adoption and the obtained results or the faced difficulties).

The results here presented can be of great utility for municipalities which are considering the adoption of this type of systems. They will help municipalities to have a better understanding of results, practices and difficulties that can be expected.

\section{Notes on contributors}

Jorge Duque works as a high-level technician in the municipality of Baião (Portugal) and is currently a $\mathrm{PhD}$ candidate in computer science at the University of Trás-os-Montes and Alto Douro (Portugal). He is the author of several publications and has presented his work at international conferences. The main area of his research is the adoption of CRM systems in municipalities.

João Varajão is Professor of information systems management and project management at the University of Trás-os-Montes e Alto Douro (Portugal). He has published widely and has served as associate editor and editorial board member for international journals. He has also served on several committees for international conferences. 
Vitor Filipe is Professor in the Engineering Department of the School of Science and Technology at the University of Trás-os-Montes e Alto Douro (Portugal). His research interests include information systems, software engineering and information technology in public institutions.

Caroline Dominguez is a Professor at the University of Trás-os-Montes e Alto Douro (Portugal), where she lectures business management. Her main research interests are in development and educational issues, project and quality management, and human resources management.

\section{References}

Bohling, T., et al., 2006. CRM implementation: effectiveness issues and insights. Journal of Service Research, 9 (2), 184-194.

Chalmeta, R., 2006. Methodology for customer relationship management. Journal of Systems and Software, 79, 1015-1024.

Chu, P.-Y., Yeh, S.-C., and Chuang, M.-C., 2008. Reengineering municipality citizen electronic complaint system through citizen relationship management. Electronic Government, an International Journal, 5 (3), 88-309.

Foss, B., Stone, M., and Ekinci, Y., 2008. What makes for CRM system success - or failure? Journal of Database Marketing \& Customer Strategy Management, 15 (2), 68-78.

Frow, P., and Payne, A., 2009. Customer relationship management: a strategic perspective. Journal of Business Market Management, 3 (1), 7-27.

Goodhue, D.L., Wixom, B.H., and Watson, H.J., 2002. Realizing business benefits through CRM: hitting the right target in the right way. MIS Quarterly Executive, 1 (2), 79-94.

GSEMA, 2009. Simplex Autárquico. GSEMA - Gabinete da Secretária de Estado da Modernização Administrativa. Available from: http://www.simplex.pt/autarquico/02 programa_06Medidas_00index.html.

King, S.F., 2006. Citizens as customers: exploring the future of CRM in UK local government. Government Information Quarterly, 24 (1), 47-63.

Lent, A., and Arend, N., 2004. Making choices: how can choice improve local public services? London: New Local Government Network.

Mendoza, E., et al., 2007. Critical success factors for a customer relationship management strategy. Information and Software Technology, 49, 913-945.

MC (Município de Cascais), 2007. Case Study CMCascais. Município de Cascais, Portugal.

Milakovich, M.E., and Gordon, G.J., 2004. Public administration in America. 8th ed. Independence, KY: Wadsworth.

Ngai, E.W.T., 2005. Customer relationship management research: an academic literature review and classification. Marketing Intelligence \& Planning, 23 (6), 582-605.

Pan, S.-L., Tan, C.-W., and Lim, E.T.K., 2006. Customer relationship management (CRM) in e-government: a relational perspective. Decision Support Systems, 42 (1), 237-250.

Payne, A., 2006. Handbook of CRM: achieving excellence in customer management. Burlington, VA: Butterworth Heinemann.

Payne, A. and Frow, P., 2005. A strategic framework for customer relationship management. Journal of Marketing, 69 (4), 167-176.

Richter, P. and Cornford, J., 2008. Customer relationship management and citizenship: technologies and identities in public services. Social Policy and Society, 7 (2), 211-220.

Saini, A., Grewal, R., and Johnson, J., 2009. Putting market-facing technology to work: organizational drivers of CRM performance. Marketing Letters, 21 (4), 365-383.

Schellong, A., 2005. CRM in the public sector: towards a conceptual research framework. Proceedings of the 2005 national conference on digital government research, Atlanta, Georgia, USA. May 15-18, 2005. 
Schellong, A. and Langenberg, T., 2007. Managing citizen relationships in disasters: Hurricane Wilma, 311 and Miami-Dade County. Proceedings of the 40th annual Hawaii international conference on system sciences, Waikoloa, Big Island, HI, USA. January 3-6, 2007.

Shin, I., 2006. Adoption of enterprise application software and firm performance. Small Business Economics, 26 (3), 241-256.

Silva, R. and Batista, L., 2007. Boosting government reputation through CRM. The International Journal of Public Sector Management, 20 (7), 588-600.

Sin, L.Y.M., Tse, A.C.B., and Yim, F.H.K., 2005. CRM: conceptualization and scale development. European Journal of Marketing, 39 (11/12), 1264-1290.

Teo, T.S.H., Devadoss, P., and Pan, S.L., 2006. Towards a holistic perspective of customer relationship management (CRM) implementation: a case study of the Housing and Development Board, Singapore. Decision Support Systems, 42 (3), 1613-1627.

Tzokas, N., and Saren, M., 2004. Competitive advantage, knowledge and relationship marketing: where, what and how? Journal of Business and Industrial Marketing, 19 (2), 124 135.

Wahab, S., Al-Momani, K., and Noor, N.A.M., 2010. The relationship between e- service quality and ease of use on customer relationship management (CRM) performance: an empirical investigation in Jordan mobile phone services. Journal of Internet Banking and Commerce, 15 (1), 1-15.

Winer, R.S., 2001. A framework for customer relationship management. California Management Review, 43 (4), 89-105.

Xavier, M.J., 2002. Citizen relationship management - concepts, tools. 6th Research Conference on Relationship Management in Atlanta, Georgia, USA. June 9-12, 2002.

Xavier, J., Gouveia, L., and Gouveia, J., 2004. Sociedade da Informação: balanço e implicações. Edições Universidade Fernando Pessoa, Porto, Portugal.

Young, J.F., Pollard C., and Gregg, P., 2007. A foundation assessment of the influence of IT management practices on customer relationship management (CRM) in a large Australian federal government agency. Australasian Journal of Information Systems, 15 (1), 77-94. 